\title{
The effects of CT guided Sacroiliac joint injection on chronic low back pain
}

\author{
Mina Youssef ${ }^{1}$ and Sherif Meleka ${ }^{2 *}$ \\ ${ }^{1}$ Medical Graduate, Alexandria University Faculty of Medicine, USA \\ ${ }^{2}$ Department of Neurosurgery, Johns Hopkins Hospital, USA
}

\begin{abstract}
Sacro-iliac joints (SIJ) disease is rarely considered as a potential source of low back pain (LBP) either because it's difficult to localize SIJ pain, or more commonly SIJ degenerative changes are a part of a more complex degenerative arthropathy, affecting multiple targets in the lumbar region causing LBP. Diagnostic tools aimed at localizing the SIJ as the pain generator are generally limited due to similarities in symptoms and signs between SIJ pain and other LBP etiologies. CT guided SIJ block became popular and more effective measure to control the low back pain immediately and for more prolonged period of time due to its safety, accuracy, efficacy and good patient tolerability for the procedure without significant complications or side effects. In our study we attempted to analyze data subsequent to SIJ injections to examine their efficacy. We collected data from 30 consecutive patients, who presented to the clinic complaining of prolonged lower back pain, explored the effects of the CT guided SIJ injections with steroids on the severity of the pain, and the outcome of the procedures on LBP. 29 patients (96.6\%) reported complete relief from their pain immediately post block, and only 1 patient had no changes between pre and post block. 18 out of 30 patients returned 1-3 months later and were found to have similar VAS pain scores as those prior to the block. We conclude that CT guided SIJ injection is a highly precise and effective tool for the diagnosis and short term relief of low back pain, due to the accuracy of the needle placement into the SIJ and the local anesthetic effect, however steroidal anti-inflammatory effects failed to demonstrate long-term benefit for those patients who suffer chronic low back pain.
\end{abstract}

\section{Introduction}

Low back pain (LBP) is a very common condition, which has a major impact on the life of a large population in the United States. Different measures are traditionally used to manage low back pain including conservative treatment; with rest or physical therapy, pharmaceutical treatment by pain medications; e.g. non-steroidal anti-inflammatory drugs, serotonergic agents or opioids. Finally, surgery is indicated for a small percentage of cases [1].

Sacro-iliac joints (SIJ) disease is rarely considered as a potential source of LBP either because it's difficult to localize SIJ pain, or more commonly SIJ degenerative changes are a part of a more complex degenerative arthropathy affecting multiple targets in the lumbar region causing LBP. It is therefore more frequent to focus on the traditionally accepted pain generators in the lumbar spine, e.g. intervertebral discs or facet joints, rather than SIJ as a potential pain generator. [2]

Fifteen millions patients in the U.S. alone are suffering from prolonged low back pain, preventing them from performing their daily activities and not responding to conservative measures or to surgical interventions [3]. Approximately 100 billion dollars are spent as the overall yearly cost for low back pain [3]. This creates a need for more efficient, long-lasting and accurate alternative measure to relieve their pain. NSAIDs are often not sufficient and cannot be supplied for prolonged periods of time due to its gastrointestinal and cardiovascular side effect [4]. CT guided SIJ block became popular and more effective measure to control the low back pain immediately and for more prolonged period of time due to its safety, accuracy, efficacy and good patient tolerability for the procedure without significant complications or side effects.
Low back pain could be the expression for mechanical SIJ arthralgia; it is usually described as a dull unilateral mild to moderate aching pain around the posterior superior iliac spine region. It is usually a debilitating pain which affects the patient's daily activity, aggravated by prolonged standing and walking. The pain is usually referred into the hip, groin, and to the lower extremities [5]. Sacroiliac joints are two paired L-shaped synovial joints formed between the articular surface of the sacrum and the ilium bones. Those two condylar joints allow minimal motility (2-18 degrees) [3], moving together in correlation. Intrinsic and extrinsic ligaments stabilize the SIJ [6]. As we grow older, SIJ surface develops angular orientation instead of the flat or planar orientation usually found in younger age [2].

Diagnostic tools aimed at localizing the SIJ as the pain generator, either by history or examination of LBP patients are generally limited due to similarities in symptoms and signs between SIJ pain and other LBP etiologies. Traditionally, fluoroscopy guided injections of the SIJ have been used both to provoke and to treat SIJ pain with limited success because of limitations due to the technique [4]. CT imaging guided technique is currently the best imaging tool for percutaneous injections to guide the injecting needle to a precise and localized anatomical structure without affecting or damaging surrounding structures such as vessels, nerves or soft tissue [7].

${ }^{\star}$ Correspondence to: Sherif Meleka, Department of Neurological Surgery, Johns Hopkins Hospital, 7220, Bloomberg Building, 1800 Orleans Street, Baltimore, MD 21287, USA, E-mail: smeleka1@jhmi.edu

Key words: sacro-iliac joints, low back pain

Received: August 05, 2020; Accepted: August 17, 2020; Published: August 20 2020 
In our study we attempted to analyze data subsequent to SIJ injections to examine their efficacy. We collected data from 30 consecutive patients aged between 43 and 91 years, who presented to the clinic complaining of prolonged lower back pain, despite long history of different treatment measures, including surgery, usually targeted towards structures other than the SIJ. We explored the effects of the CT guided SIJ injections with steroids on the severity of the pain, and the outcome of the procedures on LBP. We will also discuss the technique used for those injections. Finally, we scrutinized the commonly accepted conclusion that CT guided injections into the SIJ is currently the best and safest diagnostic and therapeutic tool on those patients who had long period of suffering from LBP.

\section{Methods}

In our study, 30 consecutive patients (cohort Table 1), who presented with chronic debilitating low back pain, despite of long-term usage of pain medications, surgeries or other procedures, were targeted. Detailed history and complete physical examination were performed, and laboratory workup and imaging studies (X rays, CT or MRI) of the lower back were ordered. CT guided SIJ steroid injections was elected to be the optimal choice to manage those patients' complaints. We confirmed the absence of contraindications to the injections such as steroid allergy, hemorrhagic diathesis, or localized skin infection. Patients were asked to record their pain ratings based on the VAS (Visual Analogue Scale). Possible complications to the injections were also discussed with the patients and an informed consent was obtained prior to the procedure. The patients were taken to the CT room where she/he was put in the prone position, and radiographic markers were placed medial to the SIJ as demonstrated in the images. The skin on the lower back was cleansed and draped in a sterile fashion, and skin wheals were raised overlying the SIJ bilaterally or unilaterally. Under CT-Fluoroscopy guidance, 3.5 inch $(10 \mathrm{~cm}) 22$-gauge spinal needles were then inserted and advanced laterally towards the SIJ, until CTFluoroscopy imaging confirmed intra articular position (Figure 1). At this point, a $1.5 \mathrm{ml}$ of $0.5 \%$ bupivacaine and $20 \mathrm{mg}$ of methyl prednisolone were injected to the SIJ unilaterally or bilaterally. The
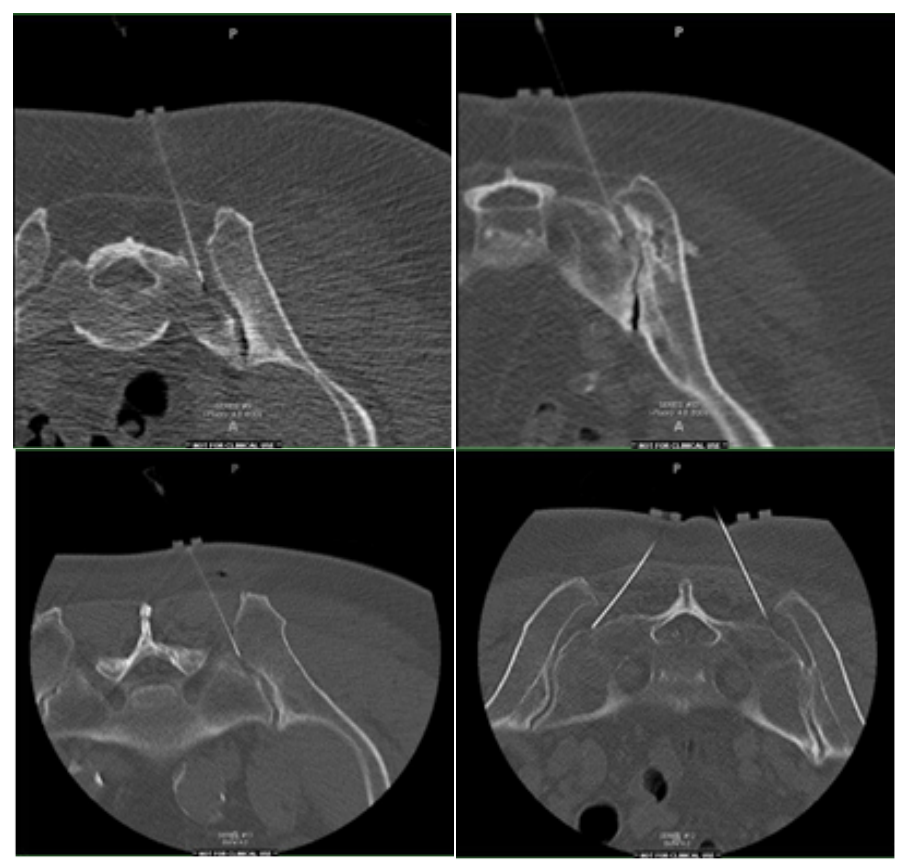

Figure 1. Four examples of intra-operative imaging of CT-guided SIJ blocks needle(s) were then removed and the skin was cleansed. The patients were then escorted out to the recovery area, where they were asked to record their pain levels, its location, and their activities then, and every thirty minutes thereafter in a pain diary for the following six hours, to check the efficacy and the potency of the injected medication, and to assess the pain severity during the recovery period. Patients came back after one to three months subsequently for a follow up visit, and their pain level was reassessed.

\section{Results}

SIJ injection under CT guidance is generally indicated for patients who had long history of low back pain that is not relieved by nonsteroidal anti-inflammatory or other medications [8]. Amongst patients who might benefit from this procedure are those who had multileveled spondylotic changes of the lumbosacral spine, also patients who had disc space narrowing compatible with degenerative disc disease, and patients with history of failed lumbar spine surgical operations, either posterior fusions and/or laminectomies.

Our patients' age group range did not make a difference, and $96.66 \%$ of the patients experienced immediate post procedural relief from their pain. This was presumably due to local anesthetic effect, as well as the accuracy and precision of the CT guidance in directing the injecting needle into the SIJs. The VAS pain scale was used to assess the severity of the pain before and after the SIJ blocks. Charts with the results were constructed to show the immediate change in the patients complains (Chart 1). Patients were asked to return in one month, and three months, for follow up to reassess their pain, and evaluate the potential long term effect of the steroids used in the SIJ injection, in order to discern between the local anesthetic and the steroid effects.

Data were gathered from two different groups of patients. The first group was those who returned for a follow-up in 1-3 months after the procedure (18 patients), and the second group comprised those who returned after 3 months or more (9 patients) for a follow up. Three patients did not return for follow up, and we failed to trace them. Data were plotted (Chart 2) to compare the VAS pre block and VAS 1-3 months post block, and (Chart 3 ) for the second group who returned after 3 months or more. Data were analyzed using the $\mathrm{Z}$ test and the $\mathrm{P}$ value to see the correlation between the Pre Block, one to three months post block, and $>3$ months post block VAS (Table 2).

29 patients (96.6\%) reported complete relief from their pain immediately post block, and only 1 patient had no changes between pre and post block (Chart 1). Patients were asked to come back for a follow up visit after one month. 18 out of 30 patients returned 1-3 months later and were found to have similar VAS pain scores as those prior to the block (Charts 2 and 4). The other group of patients (9 out of 30 patients) came after 3 months reporting similar VAS rating of their low back pain (Chart 3). 3 patients never returned for a follow up visit. Comparative analysis of the VAS values demonstrated no significant difference between those two groups (Chart 4 and 5), and P values were the same between them (Table 2).

No side effects or complications were reported following the procedure or during the follow up visits.

\section{Discussion}

The current best diagnostic tool to confirm the source for chronic LBP to be of SIJ etiology is SIJ injection under CT guidance using steroids and local anesthetic solution [9]. The diagnosis is confirmed when there is significant improvement in patients' complaints of low 
Table 1. Cohort table

\begin{tabular}{|c|c|c|c|c|c|c|c|}
\hline Age & Sex & Duration of Pain & Location of the Pain & PMH if relevant to pain & Meds Tried & PSH & $\begin{array}{l}\text { site of the } \\
\text { Block }\end{array}$ \\
\hline \multirow[t]{3}{*}{64} & $\mathrm{~F}$ & 9 Days & right side Paraspinal LBP & Grade 1 Spondylolisthesis of L4, L5 & Anti-inflammatory (Ibuprofen) & & \\
\hline & & & & Foraminal stenosis on Rt Side. & Oral Steroid & None & Left \\
\hline & & & & Lumbar Scoliosis & & & \\
\hline 60 & $\mathrm{~F}$ & 4 years & RT LBP & Diverticulosis & Tramadol, Neurontin & not relevant & RT \\
\hline \multirow[t]{3}{*}{55} & $\mathrm{~F}$ & Since she was 19 & LBP Bilaterally & Scoliosis at age of 19 & & & \\
\hline & & & & spondylosis L1, S1 & & & \\
\hline & & & & Degenerative disc disease L4,5, L5, S1 & Tramadol, Mobic, Lyrica & none & Bilateral \\
\hline 90 & $\mathrm{~F}$ & 4 months & Bil LBP & Spondylolisthesis, Lumbar stenosis & $\begin{array}{l}\text { Tramadol, acetaminophen, } \\
\text { Norvasc }\end{array}$ & Laminectomy and Fusion & Bilateral \\
\hline 62 & $\mathrm{~F}$ & 32 Years Chronic LBP & Bilateral & Fibromyalgia, osteoarthritis & $\begin{array}{l}\text { Atenolol, Allegra, } \\
\text { Celexa,Nexium }\end{array}$ & Lumbar surgery L5 Disc. & Bilateral \\
\hline \multirow[t]{2}{*}{65} & $\mathrm{~F}$ & 3 Yrs & Right LBP & Osteoarthritis, & Lyrica, Tylenol & Not Relevant & Right \\
\hline & & & & & & & Right \\
\hline 57 & $\mathrm{~F}$ & $1 \mathrm{yr}$ & Right Buttock Region & Lumbar Degenerative disease & Ambien, multivitamin & $\begin{array}{l}\text { Excision of Mole at the } \\
\text { Buttock }\end{array}$ & Bilateral \\
\hline \multirow[t]{2}{*}{76} & $\mathrm{~F}$ & $2 \mathrm{yrs}$ & Right LBP & $\begin{array}{l}\text { Multilevel Cervical spondylosis } \\
\text { mostly at C5, } 6\end{array}$ & & Not relevant & Right \\
\hline & & & & Grade 1 Spondylolisthesis & & & \\
\hline 75 & M & 5 months & Bilateral LBP & Posterior Fusion L-S1 Sacrum & Tramadol, anti-inflammatory & None & Bilateral \\
\hline \multirow[t]{3}{*}{70} & $\mathrm{~F}$ & 3 Months & LBP & History of Lumbar fusion & & $\begin{array}{l}\text { L3 L4 laminectomy, L2-L5 } \\
\text { instrumental }\end{array}$ & Bilateral \\
\hline & & & & Narrow Disc L2,3,4 & Norvasc & $\begin{array}{l}\text { She also Had } 4 \text { Left Hip } \\
\text { Surgery, Lumbar surgery }\end{array}$ & \\
\hline & & & & & & and Laminectomy & \\
\hline 56 & $\mathrm{~F}$ & $1 \mathrm{yr}$ & Left side LBP & Not relevant & Ibuprofen & T4-S1 Post Spinal Fusion & $\mathrm{Lt}$ \\
\hline 57 & $\mathrm{~F}$ & 3 months & Left LBP & Chronic Kyphoscoliosis & Ibuprofen, Norvasc & Thoracolumbar Surgery & $\mathrm{Lt}$ \\
\hline 43 & M & 3 yrs & Right LBP & Not relevant & Tylenol, Lyrica & None & Right \\
\hline 67 & M & 9 yrs & $\begin{array}{l}\text { Low Back Pain and Both } \\
\text { Legs }\end{array}$ & Not Relevant & Roxicodone, Celebrex & $\begin{array}{l}\text { L4,5 fusion, } 5 \text { hip revision } \\
\text { on left side }\end{array}$ & Right \\
\hline 79 & $\mathrm{~F}$ & 5 months & LBP & Not significant & Lyrica. & $\begin{array}{l}\text { Spinal Fusion L4, L4,5 } \\
\text { Laminectomy }\end{array}$ & Bilateral \\
\hline 79 & $\mathrm{~F}$ & 3 years & Right lower back & Colon Cancer, Hepatitis & Nexium, Tylenol & $\begin{array}{l}\text { Lumbar Foraminectomy, } \\
\text { Fusion L2-L5 }\end{array}$ & Right SIJ \\
\hline 79 & M & 9 months & Right LBP, Right Leg pain & L4-5 radiculopathy, ventral Hernia & Ibuprofen & prostatectomy & Right \\
\hline 91 & $\mathrm{~F}$ & $1 \mathrm{yr}$ & Buttock Pain & Kyphoscoliosis, and spondylosis. & hydrocodone, Darvocet, codeine & Vertebroplasty & Bilateral \\
\hline 53 & $\mathrm{~F}$ & 9 Months & Bilateral LBP & Osteoporosis & oxycodone, & None & $\begin{array}{l}\text { Bilateral } \\
\text { SIJ }\end{array}$ \\
\hline \multirow[t]{2}{*}{82} & $\mathrm{~F}$ & 7 months & Right and Lt Hip & Osteoarthritis Right hip, Lt Knee, & Naproxen & Hernia surgery & Bilateral \\
\hline & & & & Lumbar facet Syndrome & & & \\
\hline 28 & M & 5 months & Lt SIJ Pain & Advanced degenerative disc disease & Ice packs for the pain & Fusion at L4-5, L5 S1 & $\begin{array}{l}\text { Lt SIJ } \\
\text { Block }\end{array}$ \\
\hline 54 & $\mathrm{~F}$ & 6 yrs & Lt side LB, hip and thigh & Fractured sacrum, Disc hernia on L4-5 & Percocet, Valium, Motrin & Lumbar fusion surgery & Left \\
\hline 53 & M & $3 \mathrm{yrs}$ & Bilateral LBP & Lumbar and cervical spondylosis & Percocet, Oxycontin & L5-S1 Disc replacement & Bilateral \\
\hline 50 & M & 9 months & Low Back, Thigh and leg & Osteoarthritis & Nexium, Multivitamins & Not relevant & Bilateral \\
\hline 74 & M & $1 \mathrm{yr}$ & Low back & Not relevant & Lyrica, Savilla & Laminectomy & Left \\
\hline \multirow[t]{3}{*}{69} & M & chronic for $40 \mathrm{yrs}$ & & $\begin{array}{l}\text { Degenerative joint disease and lumbar } \\
\text { spine }\end{array}$ & Neurontin, oxycodone & Not relevant & Right \\
\hline & & & & $\begin{array}{l}\text { TB with infection of the spine, Potts } \\
\text { Disease. }\end{array}$ & & & \\
\hline & & & & Spinal Stenosis & & & \\
\hline \multirow[t]{2}{*}{71} & $\mathrm{~F}$ & $1 \mathrm{yr}$ & Right Lower Back & Multileveled Spondylosis & oxycodone & $\begin{array}{l}\text { Lumbar instrumentation } \\
\text { post Posterior }\end{array}$ & Right \\
\hline & & & & & & $\begin{array}{l}\text { Lumbar fusion from L2 } \\
\text { through sacrum. }\end{array}$ & \\
\hline \multirow[t]{3}{*}{77} & $\mathrm{~F}$ & 1 month & Lower Back bilaterally & $\begin{array}{l}\text { Scoliosis, L4-5, L5 S1 } \\
\text { Spondylolisthesis }\end{array}$ & Entocort, and tylenol & Laminectomy Decompress, & Bilateral \\
\hline & & & & L4-L5 Radiculopathy & & $\begin{array}{l}\text { Facetectomy, } \\
\text { foraminotomy lumbar seg }\end{array}$ & \\
\hline & & & & & & Total Knee arthroplasty. & \\
\hline
\end{tabular}




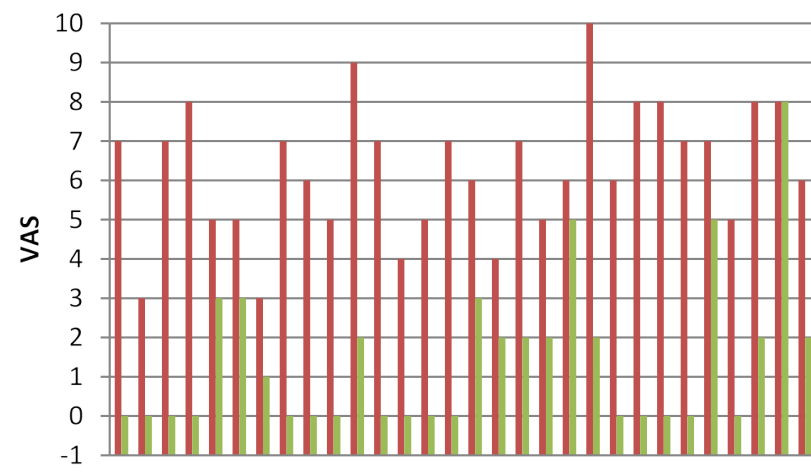

- Pre Block VAS

- Immediate Post Block

$\begin{array}{lllllllllllllll}1 & 3 & 5 & 7 & 9 & 11 & 13 & 15 & 17 & 19 & 21 & 23 & 25 & 27 & 29\end{array}$

Patients

Chart 1. Pre Block and Immediate Post Block VAS

P Value calculated from the $\mathrm{Z}$ test (Table 2)

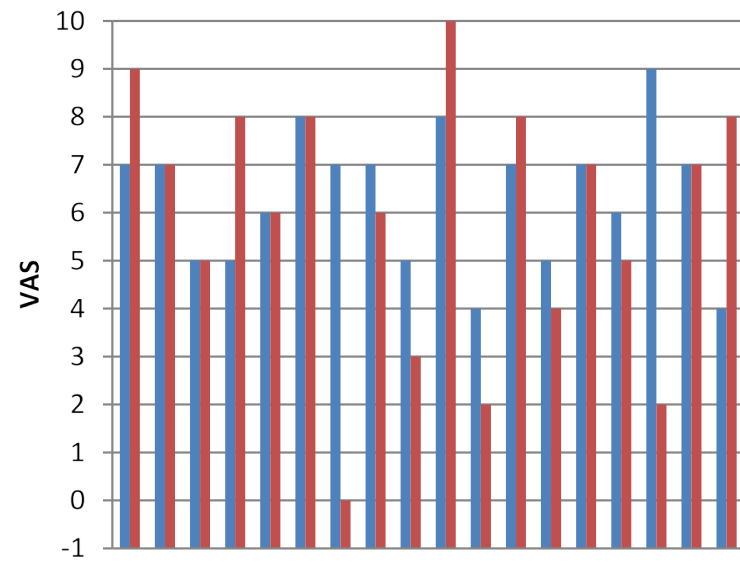

Pre Block VAS

1-3 months Post Block VAS

$\begin{array}{llllllllll}1 & 2 & 3 & 4 & 5 & 6 & 7 & 8 & 9 & 101112131415161718\end{array}$

Number of Patients

Chart 2. Pre Block and 1-3 months Post Block

P Value calculated from the $\mathrm{Z}$ test (Table 2)

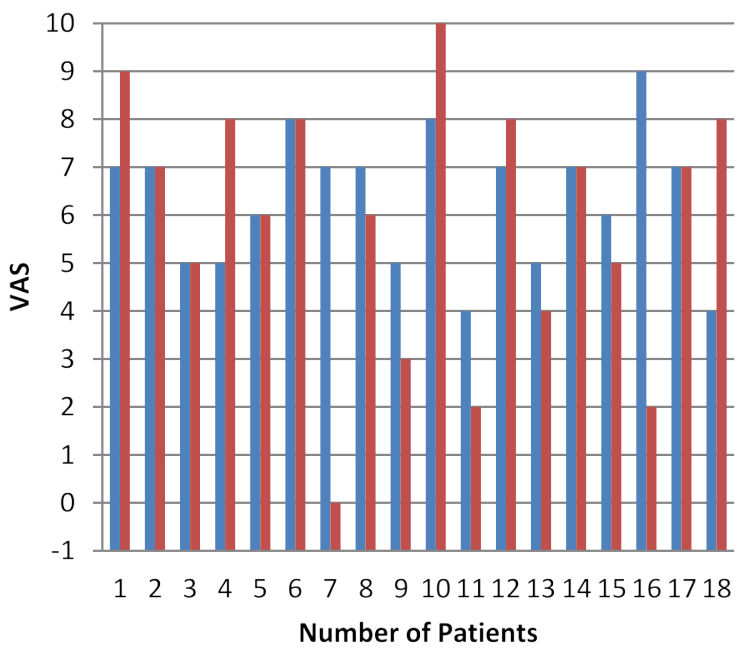

Pre Block VAS

1-3 months Post Block VAS

P Value calculated from the $\mathrm{Z}$ test (Table 2).

Chart 3. Pre Block and $>3$ Months Follow Up VAS 

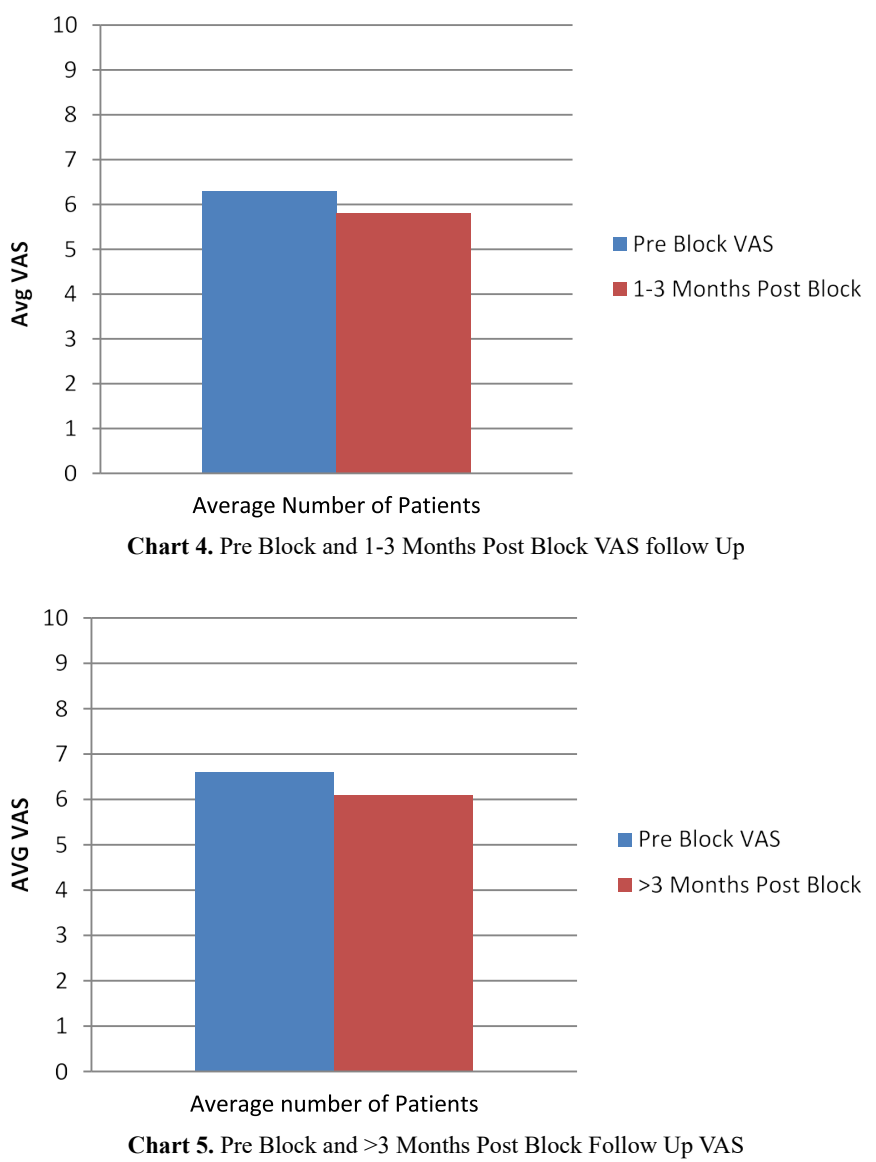

Table 2. $\mathrm{P}$ Value calculated from the $\mathrm{Z}$ test

\begin{tabular}{|l|c|c|c|c|}
\hline & Pre block & $\begin{array}{c}\text { 1 Month } \\
\text { Post block }\end{array}$ & $\begin{array}{c}\text { Pre Block } \\
\text { VAS }\end{array}$ & $\begin{array}{c}\text { 3 Months } \\
\text { Post Block }\end{array}$ \\
\hline Avg VAS & 6.3 & 5.8 & 6.6 & 6.1 \\
\hline SD & 1.4 & 2.6 & 1.6 & 2.2 \\
\hline Z & 3.6 & 2.4 & 2.9 & 2.4 \\
\hline Right-tailed P-value (Z> 1) & 0.9998 & 0.9998 & 0.9981 & 0.9998 \\
\hline Two-tailed P-value $(|\mathbf{Z}|>\mathbf{1})$ & 0.0002 & 0.0082 & 0.0019 & 0.0082 \\
\hline $\begin{array}{l}\text { Two-tailed Confidence Level } \\
(|\mathbf{Z}|<\mathbf{1})\end{array}$ & 0.0003 & 0.0164 & 0.0037 & 0.0164 \\
\hline & & 0.9836 & 0.9963 & 0.9836 \\
\hline
\end{tabular}

back pain, reported during separate office visits. In our retrospective study we examined VAS pain ratings of 30 consecutive patients thought to have SIJ pain, who received CT guided SIJ injections.

Our results demonstrate that CT guided SIJ block is effective and well-tolerated procedure for LBP patients with excellent effect on instant pain relief that starts immediately and may last for weeks or up to one month after the injection (Chart 1). However, no long term pain relief was demonstrated one month or longer following the injections. No known side effects occurred following the procedure or during the follow up visit. The pain relief is believed to be due to the local anesthetic effect, or the short term anti-inflammatory effect of the injectable steroids into the SIJ, and due to the accuracy of the needle placement under the guidance of the CT fluoroscopy into the targeted inflamed SIJ.

However there is no long term benefit from steroid injections and patients had to come back for another injection after three months. Compared to other studies $(2,3$, and 4$)$ our results were tracked for more than 3 months using a larger number of patients (27 patients) and data were plotted into charts, and analyzed data proved the short term effect of the local anesthetic injection (Chart 1), and to show that there is no difference between the mid-term (1-3 months) and the long-term effect ( $>3$ months) of the injection (Charts 4 and 5). Also we concluded that steroid effects -if any- had diminished had diminished to nonsignificant levels one month post injection. There was no difference between the two study groups in the $\mathrm{Z}$ test and the $\mathrm{P}$ value between the two groups under the investigation (Table 2).

\section{Conclusion}

We conclude that CT guided SIJ injection is a highly precise and effective tool for the diagnosis and short term relief of low back pain, due to the accuracy of the needle placement into the SIJ and the local anesthetic effect, however steroidal anti-inflammatory effects failed to demonstrate long-term benefit for those patients who suffer chronic low back pain.

\section{References}

1. Orcun SAHİN, Ali HARMAN, Rahmi Can AKGUN, İsmail Cengiz TUNCAY (2012) An Intraarticular Sacroiliac Steroid Injection Under the Guidance of Computed Tomography for Relieving Sacroiliac Joint Pain: A Clinical Outcome Study with Two Years of Follow-Up. Turk J Rheumatol 27: 165-173.

2. Gevargez A, Groenemeyer D, Schirp S, Braun M (2002) CT-guided percutaneous radiofrequency denervation of the sacroiliac joint. Eur Radiol 12: 1360-1365.

3. Boswell MV, Trescot AM, Datta S, Schultz DM, Hansen HC, et al. (2007) Interventional techniques: evidence-based practice guidelines in the management of chronic spinal pain. Pain physician 10: 7-111.

4. Hansen HC, Brown AM, Cohen SP, Swicegood JR, Colson JD, et al. (2007) Sacroiliac joint interventions: a systematic review. In Database of Abstracts of Reviews of Effects (DARE): Quality-assessed Reviews [Internet] 2007. Centre for Reviews and Dissemination (UK). Pain Physician 10: 165-184

5. http://www.biij.org/2011/1/e4

6. Park CH (2010) Comprasion of effectiveness of CT vs C-arm guided percutaneous radiofrequency lumbar facet rhizotomy. Korean J Pain 23: 137-141.

7. Silbergleit R, Mehta BA, Sanders WP, Talati SJ (2001) Imaging-guided injection techniques with fluoroscopy and CT for spinal pain management. Radiographics 21 : 927-939.

8. Colachis SC, Worden RE, Bechtol CO, Strohm BR (1963) "Movement of the sacroiliac joint in the adult male: a preliminary report". Arch Phys Med Rehabil 44: 490-498.

9. Weisl H (1954). "The ligaments of the sacroiliac joint examined with particular reference to their function". Acta Anat (Basel) 20: 201-213.

Copyright: (C2020 Youssef M. This is an open-access article distributed under the terms of the Creative Commons Attribution License, which permits unrestricted use, distribution, and reproduction in any medium, provided the original author and source are credited. 